\title{
Study on the Landscape Design of Urban Aged Community Based on Humanistic Care
}

\author{
Yafang Han \\ Xi’an Peihua University, Xi’an, Shaanxi, 710125
}

Keywords: humanistic care; urban retirement; landscape design

\begin{abstract}
With the development of society, the aging of the population has become more and more serious. Many countries are facing such problems. Chinese society has always been at the forefront of development, but the aging is more obvious. In response to this phenomenon, the country has put forward the policy of home-based care for the elderly. With the construction of the environment and the design of the landscape, it provides a good living environment for the elderly. The environment plays an important role in physical and mental health of the elderly. Under the humanistic care, pensioning has become an important measure of economic development. Starting from the practice and starting from the ordinary family, the landscape of the aged community also plays a crucial role in the activities of the elderly. This paper is mainly based on the aged community for the elderly in the humanistic care, and studies the social landscape for the aged through pensions. The purpose is to create a good landscape environment to meet the needs of the elderly, clearly put forward humanistic care as an important concept of old-age care, and pay attention to psychological and physical health of the elderly, which will be suitable for the study of the aged community landscape design to allow the elderly to get a livable environment in their later years from the outdoor activities of the market, the layout of plants, and etc.
\end{abstract}

\section{Introduction}

Introduction: The society is constantly changing. With the implementation of China's national policy on family planning, under the one-child system, many young people's parents are already elderly and society has entered an aging state. According to research and verification, China's population over the age of 60 already accounts for more than $14 \%$ of the total population. This ageing trend makes the pension issue a social problem. In order to meet the living needs of the elderly, it is necessary to improve the old-age care facilities. Especially in the urban environment, pensions need the support of national policies. The main problem of the old-age care problem is that the local old-age care environment is relatively poor, and the nursing homes with relatively favorable conditions have limited the elderly to support their old age due to economic problems. In the face of this situation, the country has proposed the dominant concept of home-based care, taking the human care of the elderly as the main target of psychological care, and using welfare and aged care institutions as its main old-age care units. Planning for an old-age living environment. The excellent living environment plays an important role in the life of the elderly. As elderly people, they hope to have a quiet and comfortable living environment in their later years. From the perspective of humanistic care, we will regard physical and mental health as a key concern and apply the landscape design of the old-age community to old-age care, which will greatly improve the lives of the elderly.

\section{The Development of Aged Community in Humanistic Care}

The concept of old-age community originated in foreign countries. It is a new way of life for the residents. It serves as a carrier for the people and society who want to live, and it plays a role in communication and contact. The old-age community refers to a type of living entity of the elderly. In this place where the elderly live, it is relatively complete from daily food to life and entertainment. This type of community-based pension is not a nursing home, and the nursing home 
is a relatively closed one. Institutions, while the community care for the elderly takes into account the advantages of nursing homes, while providing residential building services according to the characteristics of the elderly, forming a community of outdoor activities and residence. The facilities in its community are well-established and the comprehensive services are highly priced. This can not only facilitate the activities of the elderly, but also support the elderly, especially the idea of providing old-age care under the care of the humanities. On the basis of our traditional culture, we pay attention to the mental health and physical requirements of the elderly, starting from the lifestyle of the elderly, The design research of the landscape of the old-age community has solved the neglected problems of the elderly, and together with the design study, calls for the community to give the elderly more humane care. Let the design be more humanistic and add color to the elderly's outdoor life.

\section{Changes in the Psychological State of Older People under Humanistic Care}

When the elderly people enter the old age stage, the mental state will undergo certain changes. This will change with the change of physiological conditions. In this process, because the physical strength of the elderly will decline in all aspects, many things will often fail. This will put some pressure on their psychological. As society's demand for older people's work is getting lower and lower, the older people who used to be busy at work have changed their roles due to retirement. They are psychologically prone to certain gaps and negative emotions, and therefore show irritability. mood. It used to be a more important role and position in the family, but became subordinate in the family due to retirement. The relationships established in long-term work gradually lost with age. This will have a certain influence on the psychology of the elderly. Therefore, the elderly need to go out more and solve this negative psychological state through various means. In particular, community retirement with a better livable environment can help the elderly to solve them through a sound community institution and some community activities.

Because of the development of negative emotions of the elderly, it is not conducive to the health of the elderly. In such circumstances, the elderly need to have humanistic care and urgently need spiritual comfort. Through social needs, it is recognized by the society or the surrounding neighborhoods. Through this method, the physical and mental health of the elderly can be enjoyed. This is a recognition of the needs, allowing the elderly to resolve their inner repression through interpersonal relationships. This way old people feel they need to be recognized. For example, many elderly people go to square dance activities, gather together to dance, chat together, or play chess together. Through this social approach, the physical and mental health of the elderly is developed. This requires a good landscape design outside the community, which separates the need for quiet from the place where activities are needed. It is not only suitable for the elderly but also enriches outdoor activities for the elderly. Therefore, it requires a rich green environment. And suitable space for the elderly to bring a sense of residency experience.

The elderly are mainly engaged in community activities through language exchanges and activities. The main activities include playing chess and dancing. Because of their physiological function, they can only do some relaxing activities. The activities of the elderly are very regular under certain circumstances. In the early morning when the elderly exercise is relatively concentrated, after the afternoon nap and in the evening, the activities of the elderly are intensive. Of course, when the activities are carried out, the location of the elderly is also relatively fixed. According to their own interests and needs, some elderly people prefer to exercise. Usually, they choose more empty places with green plants. Some elderly people like to sing and they will Choose a location with strong concentration. All in all, the elderly have their own direction of development. Older people need a certain amount of hidden space to perform their own activities. This is to seek psychological satisfaction, that is, self-protection awareness. Some old people like to observe the large space environment through small spaces such as sheltered by small trees such as trees or small buildings. This is an activity mode for the elderly through the activities and psychology of the elderly. The change of activities can make the overall planning of the community's landscape. From the coverage of green plants and some small buildings can become an indispensable landscape in 
the community.

\section{Explore the Design Landscape of Aged Community in Humanistic Care}

The design of the community pension landscape needs to meet some specific characteristics of the elderly. Both the physical and mental aspects of the elderly tend to be aging. This requires consideration of the overall living environment of the elderly and planning from the overall environment. When designing again, security needs to be considered as the main principle. This is the main detail of the infrastructure. First of all, it is necessary to create a sense of security for the elderly community, to plan the activities of the elderly and the need for activity areas, and then to understand the activities of the elderly spontaneously organized activities, the impact of the landscape on the elderly Combine with the safety of the activity and then design it. In the landscape design, it needs to be controlled on a scale. Because the elderly are at this age stage, they have a higher requirement for privacy. They mainly like to enjoy a quiet environment and feel a sense of security. There is also a need to use good materials in building materials to make the elderly feel good about outdoor activities. For the safety of service facilities need to pass high quality and ensure safety, such as the logo of outdoor activities or some green landscape design Will give the elderly a certain degree of safety, because the elderly's age gradually increased, their eyesight, etc. are not very good, in the design of the logo need to use better materials, more eye-catching colors to produce, reduce security risks.

The main users of the urban elderly care community are the elderly, and the landscape design is carried out under the needs of the elderly. This has a very important effect on the activities and leisure of the elderly, especially the design needs to pay attention to its functionality. The activities of the elderly are generally divided into two types. One is to perform entertainment in a relatively quiet manner, such as playing chess and card games, and the other is to exist in the form of sports, such as bending, punching, etc. All need some site planning. In the planning of the landscape, the surrounding design can be integrated into it. If the elderly prefer a more quiet activity, there can be a separate chess room. If the elderly are keen on outdoor sports, this activity can be set in an individual place and the whole residence can be set. The design of the area is relatively loose, and the green plants are built in the community. They can be more comfortable pavilions. Some plants can be planted on this area. Especially in the summer, elderly people can enjoy outdoor activities while enjoying the outdoor environment. The utilization rate increases.

The landscape design of the elderly care community should not only focus on functionality, but also need to be controlled from the perspective of comfort from the details of the design, reflecting that the elderly community landscape design can bring a certain degree of comfort to the elderly. This requires starting from the psychology of the elderly, designing from a humanistic perspective, and harmonizing the outdoor landscape with the interior. Whether looking from the outside or looking from the inside indoors, it can promote the psychological pleasure of the elderly. The use of the entire space creates a local warmth, which is conducive to the enjoyment of space for the elderly in Jingyi. In the old-age community, it is necessary to highlight the green plants in the landscape, because the thriving green plants give the elderly a feeling of physical and mental comfort and will be different. The importance of collocation of trees and the design and construction of the issues for the elderly from all parties are the full enjoyment of the elderly in the community environment.

For the elderly, health not only stays in the health of the body, it should also pay attention to mental health. In the landscape design, we need to follow a healthy lifestyle. Especially in landscape design, the space for greening needs to be gradually expanded. In the process of recreation, outdoor activities can be applied to elderly activity and recreation areas. These instruments need to meet the activity needs of the elderly, and the activities of the ground and Places to deal with anti-skid facilities, add more rest areas to ensure that the elderly can rest after exercise. Extending the area of greening is mainly to improve the living environment of the community, adjust the environment through greening, and match healthy places with green areas. In this process, landscape design needs to be integrated into the physical and mental health of the elderly. While performing health and entertainment, enjoy physical and mental pleasure. In the 
community, landscape gardening can also be designed to allow many elderly people who like to do their hands to entertain some items such as flowers, so that they can play a beneficial role in the health of the elderly.

\section{The External Landscape Design of Aged Community in Humanistic Care}

In the elderly care community, the external landscape design is very important, especially in the way of communicating with the outside. The design of the road plays an important role in the development of the community. First of all, we need to make reasonable plans based on the characteristics of the community's terrain and the area it covers. Carry out transportation functions and life functions. Traffic roads are divided into roadways and walkways. Roadways are mainly built around communities. Walking tracks are designed to facilitate the travel of elderly people. In the process of community planning, attention must be paid to separation between people and vehicles. This will allow Older people live more safely. This way the walkway will not be disturbed by the outside. The parking of community vehicles is to set up a relatively safe underground parking lot. Such a parking lot can reduce the parking of road vehicles and reduce potential safety hazards. At the same time, a fire exit must be designed to ensure the overall safety of the community. It is also necessary to take into consideration the road building materials and rest places in the community and focus on the convenience of the elderly as the main landscape design.

In the elderly care community, the main sidewalk is a path that mainly connects residential areas and entrance function spaces. When designing the main sidewalks, there are certain requirements. First of all, such a path should be flat and straight, and it must be curved so that it is not conducive to the elderly. Once again, the line should not be too long. If the straight line is too long, a green area can be added around the area to attract the attention of the elderly. This will not allow the elderly to feel tired during walking, and they will be psychologically stretched. There is also a part of the sidewalk, which is a kind of road that is second only to the main street. In this kind of road design, it is necessary to increase the interest and combine the design of the road with the surrounding facilities to make the width smaller. The road is designed and the circuit design is relatively free.

\section{Conclusion}

The urban elderly care community landscape design under the humanistic concern is mainly to analyze the pension groups, design according to the physiological characteristics and psychological needs of the elderly, from indoor to outdoor, from the greening of the community to the design of the road, for the elderly People provide a comfortable and safe community environment to meet the needs of the elderly, integrate humanistic care into landscape design, create a community that belongs to the elderly, and pay attention to the healthy life of the elderly, allowing the elderly to relax physically and mentally.

\section{References}

[1] Xu Cong. Research on building space design of elderly care community based on humanistic care[D]. Qingdao Technological University, 2014.

[2] Xu Zihui. Livable landscape design in the elderly community [D]. Tianjin University of Science and Technology, 2017.

[3] Yang Xiaofang. Research on Landscape Environment Design of Elderly Care Community[D]. Anhui University, 2017.

[4] Zhang Wen. Research on rural aged care architecture design for urban residents[D]. Jilin Architectural University, 2017.

[5] Min Jiaofen. Research on the environment design of nursing homes under the concept of 
humanistic care [D]. Guangxi Normal University, 2016.

[6] Wang Qi. Study on the Rehabilitation Environment Design of Elderly Care Community Based on Humanistic Care [D]. Shaanxi University of Science and Technology, 2016.

[7] Dou Yongjia. Research on Sustainability Updating of Public Space in Existing Residential District [D]. Southeast University, 2017.

[8] Yan Xue. Landscape Planning of Baoting Wanrollan Pension Community Based on Tourism Pension [D]. Fujian Agriculture and Forestry University, 2017. 